\title{
Behavioral deficits in sepsis-surviving rats induced by cecal ligation and perforation
}

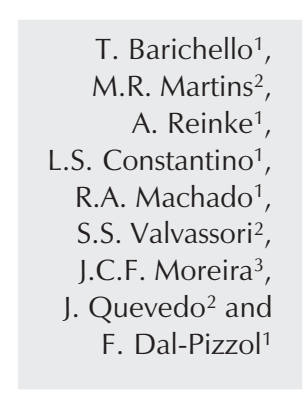

\author{
${ }^{1}$ Laboratório de Fisiopatologia Experimental, \\ ${ }^{2}$ Laboratório de Neurociências, Universidade do Extremo Sul Catarinense, \\ Criciúma, SC, Brasil \\ ${ }^{3}$ Centro de Estresse Oxidativo, Departamento de Bioquímica, \\ Instituto de Ciências Básicas da Saúde, \\ Universidade Federal do Rio Grande do Sul, Porto Alegre, RS, Brasil
}

\section{Correspondence \\ F. Dal-Pizzol \\ Laboratório de Fisiopatologia \\ Experimental \\ Universidade do Extremo Sul \\ Catarinense \\ 88006-000 Criciúma, SC \\ Brasil \\ E-mail: pizzol.ez@terra.com.br \\ Research supported by FAPESC, CNPq and UNESC.}

Received October 4, 2006 Accepted April 18, 2007

\section{Abstract}

Sepsis and its complications are the leading causes of mortality in intensive care units, accounting for 10-50\% of deaths. Intensive care unit survivors present long-term cognitive impairment, including alterations in memory, attention, concentration, and/or global loss of cognitive function. In the present study, we investigated behavioral alterations in sepsis-surviving rats. One hundred and ten male Wistar rats (3-4 months, $250-300 \mathrm{~g}$ ) were submitted to cecal ligation and puncture (CLP), and 44 were submitted to sham operation. Forty-four rats (40\%) survived after CLP, and all sham-operated animals survived and were used as control. Twenty animals of each group were used in the object recognition task (10 in short-term memory and 10 in long-term memory), 12 in the plus-maze test and 12 in the forced swimming test. Ten days after surgery, the animals were submitted individually to an object recognition task, plus-maze and forced swimming tests. A significant impairment of short- and long-term recognition memory was observed in the sepsis group (recognition index 0.75 vs 0.55 and 0.74 vs 0.51 for short- and long-term memory, respectively $(\mathrm{P}<0.05)$. In the elevated plus-maze test no difference was observed between groups in any of the parameters assessed. In addition, sepsis survivors presented an increase in immobility time in the forced swimming test (180 vs $233 \mathrm{~s}, \mathrm{P}<0.05)$, suggesting the presence of depressive-like symptoms in these animals after recovery from sepsis. The present results demonstrated that rats surviving exposure to CLP, a classical sepsis model, presented recognition memory impairment and depressive-like symptoms but not anxietylike behavior.
Key words

- Sepsis survivors

- Recognition memory

- Plus-maze test

- Forced swimming test

- Cecal ligation and puncture

- Cognitive impairment 


\section{Introduction}

Sepsis and its complications are a leading cause of mortality, accounting for 10$50 \%$ of deaths on intensive care units (1-4). Several studies have been performed to investigate the role of peripheral organs such as lungs, liver, gut, and kidneys in sepsis development (5), but the participation of the central nervous system during sepsis has been studied less. Septic encephalopathy represents brain dysfunction due to sepsis or the systemic inflammatory response syndrome, and has been reported to occur in $8-70 \%$ of septic patients depending on the inclusion criteria employed (6-8).

Survivors of critical care, including septic patients, may have persistenty compromised organ function, which may result in symptoms such as dyspnea, fatigue, depression, and impaired functional status. Recently, several studies have demonstrated that critical care survivors present long-term cognitive impairment, including alterations in memory, attention, concentration, and/or global loss of cognitive function (9-17). However, the neurobiological mechanisms involved in this cognitive impairment remain unclear.

A recent study evaluating apoptosis and vulnerability of different brain regions induced by systemic inflammation concluded that the hippocampus is the most vulnerable region during experimental sepsis (18). In this context, murine models of cecal ligation and perforation (CLP) are clinically relevant since they induce a polymicrobial sepsis that mimics human sepsis (19-22). The CLP model has contributed to the elucidation of the pathogenesis and to the determination of new therapies in sepsis $(19,20)$. Shimizu et al. (23) demonstrated that $24 \mathrm{~h}$ after CLP animals presented learning impairment in passive avoidance retention. Moreover, we recently reported that CLP-induced sepsis survivors presented learning, aversive and spatial memory impairment when submitted to behavioral tasks 10 days after CLP (21) and learning and aversive memory impairment lasting up to 30 days after CPL (22). Thus, CLP seems to be a good model for the study of cognitive and emotional alterations as late manifestation of sepsis.

Therefore, the objective of the present study was to determine changes in recognition memory and the presence of anxiety- or depressive-like symptoms in severe sepsissurviving rats.

\section{Material and Methods}

\section{Subjects}

Male Wistar rats (3-4 months, 220-310 g) were obtained from our breeding colony (UNESC). The animals were housed 5 to a cage with food and water available ad libitum and were maintained on a 12-h light/ dark cycle (lights on at 7:00 am). All experimental procedures involving animals were performed in accordance with the NIH Guide for the Care and Use of Laboratory Animals and the Brazilian Society for Neuroscience and Behavior $(\mathrm{SBNeC})$ recommendations for animal care.

\section{Cecal ligation and perforation surgery}

The animals were subjected to CLP as previously described (19-22). Briefly, rats were anesthetized with a mixture of ketamine $(80 \mathrm{mg} / \mathrm{kg})$ and xylazine $(10 \mathrm{mg} / \mathrm{kg})$, given intraperitoneally. Under aseptic conditions, a 3-cm midline laparotomy was performed to allow exposure of the cecum with the adjoining intestine. The cecum was tightly ligated with a 3.0-silk suture at its base, below the ileocecal valve, and was perforated once with a 14-gauge needle. The cecum was then gently squeezed to extrude a small amount of feces from the perforation site returned to the peritoneal cavity, and the laparotomy was closed with 4.0-silk sutures. Animals were resuscitated with normal sa- 
line $(50 \mathrm{~mL} / \mathrm{kg}$ subcutaneous) immediately and $12 \mathrm{~h}$ after CLP. All animals were returned to their cages with free access to food and water. In this model septic rats become bacteremic with Gram-negative enteric organisms. In the sham-operated group the rats were submitted to all surgical procedures but the cecum was neither ligated nor perforated.

\section{Treatment protocols}

After surgery, the sepsis group received "basic support" (50 mL/kg saline immediately and $12 \mathrm{~h}$ after CLP plus $30 \mathrm{mg} / \mathrm{kg}$ ceftriaxone and $25 \mathrm{mg} / \mathrm{kg}$ clindamycin every $6 \mathrm{~h}$ for a total of 3 days). The sham-operated group received only $50 \mathrm{~mL} / \mathrm{kg}$ saline immediately and $12 \mathrm{~h}$ after surgery and the volume of saline corresponding to antibiotic administration. To perform behavior experiments 44 animals were sham-operated and the survival in this group was $100 \% ; 10$ animals were used as control to the shortterm memory in the object recognition task, 10 animals were used as control to the longterm memory in the object recognition task, 12 animals were used as control to the plusmaze test, and 12 animals were used as control to the forced swimming test. One hundred and ten animals were submitted to CLP and $40 \%$ of these animals survived to perform behavioral tests $(\mathrm{N}=44)$. These animals were divided as follows: 10 animals were used in the short-term memory object recognition task, 10 animals were used in the long-term memory object recognition task, 12 animals were used in the plus-maze test, and 12 animals were used in the forced swimming test. The number of survivors agreed with previous reports from our group (19-20).

\section{Behavioral tests}

Ten days after surgery the animals were submitted individually to the object recognition task, elevated plus-maze or forced swimming tests. All behavioral procedures were conducted between 13:00 and 16:00 $\mathrm{h}$ in a sound-isolated room. All behavioral tests were recorded by an observer who was blind to the animal group.

\section{Object recognition}

The apparatus and procedures for the object recognition task have been described elsewhere $(24,25)$. Briefly, the task took place in a 40 x 50 -cm open field surrounded by $50-$ $\mathrm{cm}$ high walls made of plywood with a frontal glass wall. The floor of the open field was divided into 12 equal rectangles by black lines. All animals were submitted to a habituation session where they were allowed to freely explore the open field for $5 \mathrm{~min}$. No objects were placed in the box during the habituation trial. Crossings of the black lines and rearings performed in this session were evaluated as locomotor and exploratory activity, respectively.

Twenty-four hours after habituation, training was conducted by placing individual rats for $5 \mathrm{~min}$ in the field, in which two identical objects (objects A1 and A2; both being cubes) were positioned in two adjacent corners, $10 \mathrm{~cm}$ from the walls. In a short-term recognition memory test given $1.5 \mathrm{~h}$ after training, the rats explored the open field for $5 \mathrm{~min}$ in the presence of one familiar (A) and one novel (B, a pyramid with a square-shaped base) object. All objects had similar textures (smooth), colors (blue), and sizes (weight 150-200 g), but distinctive shapes. A recognition index calculated for each animal is reported as the ratio $\mathrm{TB} /(\mathrm{TA}+\mathrm{TB})(\mathrm{TA}=$ time spent exploring the familiar object $\mathrm{A}$; $\mathrm{TB}=$ time spent exploring the novel object $\mathrm{B}$ ). Between trials the objects were washed with $10 \%$ ethanol solution. In a long-term recognition memory test given $24 \mathrm{~h}$ after training, the same rats were allowed to explore the field for $5 \mathrm{~min}$ in 
the presence of the familiar object $\mathrm{A}$ and $\mathrm{a}$ novel object $\mathrm{C}$ (a sphere with a squareshaped base). Recognition memory was evaluated as done for the short-term memory test. Exploration was defined as sniffing (exploring the object 3-5 cm away from it) or touching the object with the nose and/or forepaws.

\section{Elevated plus-maze}

The elevated plus-maze task used in animal models of anxiety has been described in detail elsewhere $(26,27)$. Briefly, the apparatus consisted of two open arms $(50 \times 10$ $\mathrm{cm})$ and two enclosed arms $(50 \times 10 \times 40 \mathrm{~cm})$ arranged in such a way that the two arms of each type were opposite to each other, and a central platform $(5 \times 5 \mathrm{~cm})$. The maze's height was $50 \mathrm{~cm}$ and the tests were conducted under dim red light. Animals were exposed for $5 \mathrm{~min}$ to the red light in their own home cages before the testing procedure. Next, they were placed individually on the central platform of the plus-maze facing an open arm. During a 5-min test period the following measurements were recorded by two observers: the number of entries, the

Figure 1. Object recognition task. No significant difference was observed in the numbers of crossings and rearings in the habituation session (Student $t$ test). Data are reported as means \pm SEM (A). The sepsis group presented a significant impairment of novel object recognition memory compared to the sham group (B). Results are reported as median (interquartile ranges) recognition indexes in training, short-term (STM) and long-term memory (LTM) retention test trials. $\mathrm{N}=10$ animals per group. ${ }^{*} \mathrm{P}<0.05$ compared to the sham group (Mann-Whitney U-test).

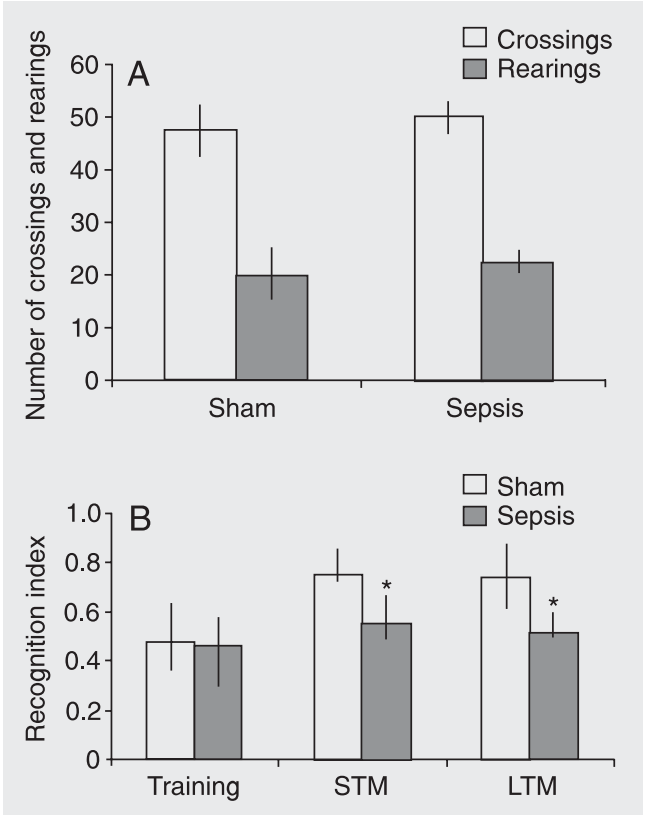

time spent in the open and closed arms, and the total number of arm entries.

\section{Forced swimming test}

The forced swimming test was conducted according to previous reports (28-30). Briefly, the test involves two exposures to a cylindrical water tank in which rats cannot touch the bottom or from which they cannot escape. The tank is made of transparent Plexiglas and is $80 \mathrm{~cm}$ tall, $30 \mathrm{~cm}$ in diameter, and filled with water $\left(22-23^{\circ} \mathrm{C}\right)$ to a depth of $40 \mathrm{~cm}$. Water in the tank was changed after each rat. For the first exposure, rats were placed in the water for $15 \mathrm{~min}$ (pre-test session). Twenty-four hours later the rats were placed in the water again for a 5-min session (test session). Behavior was videotaped for later analysis, and the periods of immobility, swimming, and struggling time were recorded. The rats were judged to be immobile whenever they stopped swimming and remained floating in the water, with their head just above water level.

\section{Statistical analysis}

Data for recognition indexes are reported as median and interquartile ranges. Comparisons among groups were performed using Mann-Whitney U-tests. Recognition indexes within individual groups were analyzed by Wilcoxon tests. The data for the elevated plus-maze and forced swimming tests are reported as means \pm SEM and were analyzed by the Student $t$-test. In all comparisons, $\mathrm{P}<0.05$ indicated statistical significance.

\section{Results}

\section{Object recognition}

In the habituation session, no significant differences were observed in the number of crossings or rearings $(\mathrm{P}=0.56$; Figure $1 \mathrm{~A})$. 
In Figure 1B, Wilcoxon tests showed that the sham group, but not the sepsis group, spent a significantly higher percentage of time exploring the novel object during either short- or long-term retention test sessions in comparison with the training trial. In addition, the sepsis group presented a significant reduction in the recognition index in shortand long-term recognition retention tests compared to the sham group (Mann-Whitney U-test, $\mathrm{P}<0.05)$. The results indicate that sepsis survivors presented an impairment of novel object recognition memory.

\section{Elevated plus-maze}

No statistically significant difference was observed in the number of entries $(\mathrm{P}=0.65)$ or in the time spent in the arms $(\mathrm{P}=0.51)$ between groups.

\section{Forced swimming test}

In the test session (5 min), $24 \mathrm{~h}$ after the pretest session (15 min), we observed a significant increase in the immobility time in the sepsis group compared to the sham group $(\mathrm{P}<0.05)$, as shown in Figure 2.

\section{Discussion}

Previous reports involving intensive care unit survivors demonstrated cognitive impairment at discharge from the hospital (917). In long-term follow-up studies most patients showed improvement in overall cognitive function; however, some cognitive skills, such as memory, were not completely recovered $(9,13,14)$. The mechanisms involved in these cognitive impairments remain unclear. In recent reports we demonstrated that CLP, a clinically relevant model of sepsis in rats, presented impairment in learning and memory. Our results were clinically relevant since 10 and 30 days after CLP the animals had fully recovered with no signs of infection or motor alterations $(21,22)$.
We have recently reported aversive and spatial memory impairments in severe sepsis-surviving rats $(21,22)$. The present study investigated this issue in rats trained in an object recognition task. This task, originally developed by Ennaceur and Delacour (31), is based on the tendency of rodents to explore a novel object more than a familiar one. Because no rewarding or aversive stimulation is used during training, the learning occurs under conditions of relatively low stress or arousal (31). Here we found that sepsis-surviving rats presented significant impairment of novel object recognition memory. These findings are relevant since the novel object recognition task in rodents is a nonspatial, nonaversive memory test, in contrast to our previous reports $(21,22)$. In addition, the object recognition task has also been increasingly used as a powerful experimental tool to assess drug effects on memory and to investigate the neural mechanisms underlying learning and memory $(24,25,32-35)$.

In the elevated plus-maze, a validated test to evaluate anxiety-like behavior (26), no differences were demonstrated between groups, indicating that sepsis survivors did not presented anxiety-like symptoms after recovery from disease.

Sepsis survivors presented depressivelike symptoms assessed in the forced swimming test. The time of immobility was significantly longer in the sepsis group. The original view of the forced swimming test offered by Porsolt (28) was that of a model of depression with features similar to those

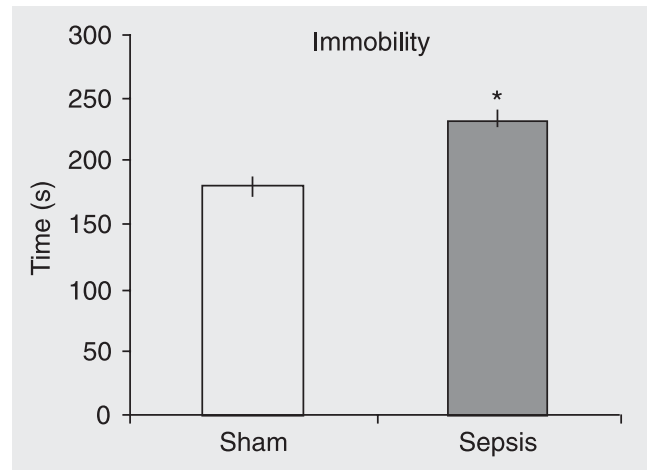

Figure 2. Forced swimming test. The sepsis group showed a significant increase in the time of immobility compared to the sham group. Data are reported as means $\pm \mathrm{SEM}$ for $\mathrm{N}=12$ animals per group. ${ }^{*} \mathrm{P}<0.05 \mathrm{com}$ pared to the sham group (Student $t$-test). 
of the learned helplessness model but technically easier to produce. The internal affective state of rodents after exposure to the initial swim in the forced swimming test was labeled as 'behavioral despair'. The pretest swim induction procedure has been proposed to be similar to the initial session that induces learned helplessness by exposing rats to inescapable stress. Induction of learned helplessness produces broad-ranging behavioral deficits in affect, cognition, sleep, and motor performance that closely resemble many of the symptoms of depression (36). Additionally, as described above, the sepsissurviving group did not present locomotor activity impairment, supporting the idea that the longer immobility time in the sepsis group was related to depressive-like symptoms. This finding agrees with clinical studies that show depressive symptoms in survivors of severe diseases such as sepsis and septic shock $(9,11-13,15)$.

In summary, our results demonstrated that survivors of CLP, a classical sepsis model, presented recognition memory impairment and depressive-like symptoms but not anxiety-like behavior. These findings, together with our previous reports $(21,22)$, indicate that the CLP model could be a good research tool for the study of the biological mechanisms involved in the behavioral alterations secondary to sepsis.

\section{References}

1. Brun-Buisson C. The epidemiology of the systemic inflammatory response. Intensive Care Med 2000; 26 (Suppl 1): S64-S74.

2. Friedman $\mathrm{G}$, Silva $\mathrm{E}$, Vincent $\mathrm{JL}$. Has the mortality of septic shock changed with time. Crit Care Med 1998; 26: 2078-2086.

3. Hotchkiss RS, Karl IE. The pathophysiology and treatment of sepsis. N Engl J Med 2003; 348: 138-150.

4. Tran DD, Groeneveld AB, van der Meulen J, Nauta JJ, Strack van Schijndel RJ, Thijs LG. Age, chronic disease, sepsis, organ system failure, and mortality in a medical intensive care unit. Crit Care Med 1990; 18: 474-479.

5. O'Brien JM Jr, Ali NA, Abraham E. Year in review in critical care, 2004: sepsis and multi-organ failure. Crit Care 2005; 9: 409-413.

6. Sprung CL, Peduzzi PN, Shatney $\mathrm{CH}$, Schein RM, Wilson MF, Sheagren JN, et al. Impact of encephalopathy on mortality in the sepsis syndrome. The Veterans Administration Systemic Sepsis Cooperative Study Group. Crit Care Med 1990; 18: 801-806.

7. Young GB, Bolton CF, Austin TW, Archibald YM, Gonder J, Wells GA. The encephalopathy associated with septic illness. Clin Invest Med 1990; 13: 297-304.

8. Bleck TP, Smith MC, Pierre-Louis SJ, Jares JJ, Murray J, Hansen CA. Neurologic complications of critical medical illnesses. Crit Care Med 1993; 21: 98-103.

9. Angus DC, Musthafa AA, Clermont G, Griffin MF, Linde-Zwirble WT, Dremsizov TT, et al. Quality-adjusted survival in the first year after the acute respiratory distress syndrome. Am J Respir Crit Care Med 2001; 163: 1389-1394.

10. Gordon SM, Jackson JC, Ely EW, Burger C, Hopkins RO. Clinical identification of cognitive impairment in ICU survivors: insights for intensivists. Intensive Care Med 2004; 30: 1997-2008.

11. Granja C, Dias C, Costa-Pereira A, Sarmento A. Quality of life of survivors from severe sepsis and septic shock may be similar to that of others who survive critical illness. Crit Care 2004; 8: R91-R98.

12. Granja C, Lopes A, Moreira S, Dias C, Costa-Pereira A, Carneiro A. Patients' recollections of experiences in the intensive care unit may affect their quality of life. Crit Care 2005; 9: R96-R109.

13. Heyland DK, Hopman W, Coo H, Tranmer J, McColl MA. Long-term health-related quality of life in survivors of sepsis. Short Form 36: a valid and reliable measure of health-related quality of life. Crit Care Med 2000; 28: 3599-3605.

14. Hopkins RO, Weaver LK, Pope D, Orme JF, Bigler ED, Larson-Lohr $V$. Neuropsychological sequelae and impaired health status in survivors of severe acute respiratory distress syndrome. Am J Respir Crit Care Med 1999; 160: 50-56.

15. Hopkins RO, Weaver LK, Collingridge D, Parkinson RB, Chan KJ, Orme JF Jr. Two-year cognitive, emotional, and quality-of-life outcomes in acute respiratory distress syndrome. Am J Respir Crit Care Med 2005; 171: 340-347.

16. Hough CL, Curtis JR. Long-term sequelae of critical illness: memories and health-related quality of life. Crit Care 2005; 9: 145-146.

17. Jackson JC, Gordon SM, Ely EW, Burger C, Hopkins RO. Research issues in the evaluation of cognitive impairment in intensive care unit survivors. Intensive Care Med 2004; 30: 2009-2016.

18. Semmler A, Okulla T, Sastre M, Dumitrescu-Ozimek L, Heneka MT. Systemic inflammation induces apoptosis with variable vulnerability of different brain regions. J Chem Neuroanat 2005; 30: 144-157.

19. Ritter C, Andrades M, Frota Junior ML, Bonatto F, Pinho RA, Polydoro $\mathrm{M}$, et al. Oxidative parameters and mortality in sepsis induced by cecal ligation and perforation. Intensive Care Med 2003; 29: 1782-1789.

20. Ritter C, Andrades ME, Reinke A, Menna-Barreto S, Moreira JC, Dal-Pizzol F. Treatment with $\mathrm{N}$-acetylcysteine plus deferoxamine protects rats against oxidative stress and improves survival in sepsis. Crit Care Med 2004; 32: 342-349.

21. Barichello T, Martins MR, Reinke A, Feier G, Ritter C, Quevedo J, et al. Cognitive impairment in sepsis survivors from cecal ligation and perforation. Crit Care Med 2005; 33: 221-223.

22. Barichello T, Martins MR, Reinke A, Feier G, Ritter C, Quevedo J, et al. Long-term cognitive impairment in sepsis survivors. Crit Care 
Med 2005; 33: 1671.

23. Shimizu I, Adachi N, Liu K, Lei B, Nagaro T, Arai T. Sepsis facilitates brain serotonin activity and impairs learning ability in rats. Brain Res 1999; 830: 94-100.

24. Rosa RM, Flores DG, Appelt HR, Braga AL, Henriques JA, Roesler R. Facilitation of long-term object recognition memory by pretraining administration of diphenyl diselenide in mice. Neurosci Lett 2003; 341: 217-220.

25. Schröder N, O'Dell SJ, Marshall JF. Neurotoxic methamphetamine regimen severely impairs recognition memory in rats. Synapse 2003; 49: 89-96.

26. Pellow S, Chopin P, File SE, Briley M. Validation of open:closed arm entries in an elevated plus-maze as a measure of anxiety in the rat. J Neurosci Methods 1985; 14: 149-167.

27. Rickels K, Schweizer EE. Current pharmacotherapy in anxiety and panic. In: Meltzer HY (Editor), Psychopharmacology: The third generation of progress. New York: Raven Press; 1987. p 1193-1203.

28. Porsolt RD. Animal model of depression. Biomedicine 1979; 30: 139-140.

29. Einat $H$, Clenet $F$, Shaldubina A, Belmaker $\mathrm{RH}$, Bourin $\mathrm{M}$. The antidepressant activity of inositol in the forced swim test involves 5$\mathrm{HT}(2)$ receptors. Behav Brain Res 2001; 118: 77-83.

30. Einat H, Yuan P, Gould TD, Li J, Du J, Zhang L, et al. The role of the extracellular signal-regulated kinase signaling pathway in mood modulation. J Neurosci 2003; 23: 7311-7316.

31. Ennaceur A, Delacour J. A new one-trial test for neurobiological studies of memory in rats. 1: Behavioral data. Behav Brain Res 1988; 31: 47-59.

32. Baker KB, Kim JJ. Effects of stress and hippocampal NMDA receptor antagonism on recognition memory in rats. Learn Mem 2002; 9: 58-65.

33. Okuda S, Roozendaal B, McGaugh JL. Glucocorticoid effects on object recognition memory require training-associated emotional arousal. Proc Natl Acad Sci U S A 2004; 101: 853-858.

34. Rampon C, Tang YP, Goodhouse J, Shimizu E, Kyin M, Tsien JZ. Enrichment induces structural changes and recovery from nonspatial memory deficits in CA1 NMDAR1-knockout mice. Nat Neurosci 2000; 3: 238-244.

35. Tang YP, Shimizu E, Dube GR, Rampon C, Kerchner GA, Zhuo M, et al. Genetic enhancement of learning and memory in mice. Nature 1999; 401: 63-69.

36. Weiss J, Kilts C. Animal models of depression and schizophrenia. In: Nemeroff C, Schatzberg AS (Editors), Textbook of psychopharmacology. New York: American Psychiatric Association Press; 1998. p 88-123. 